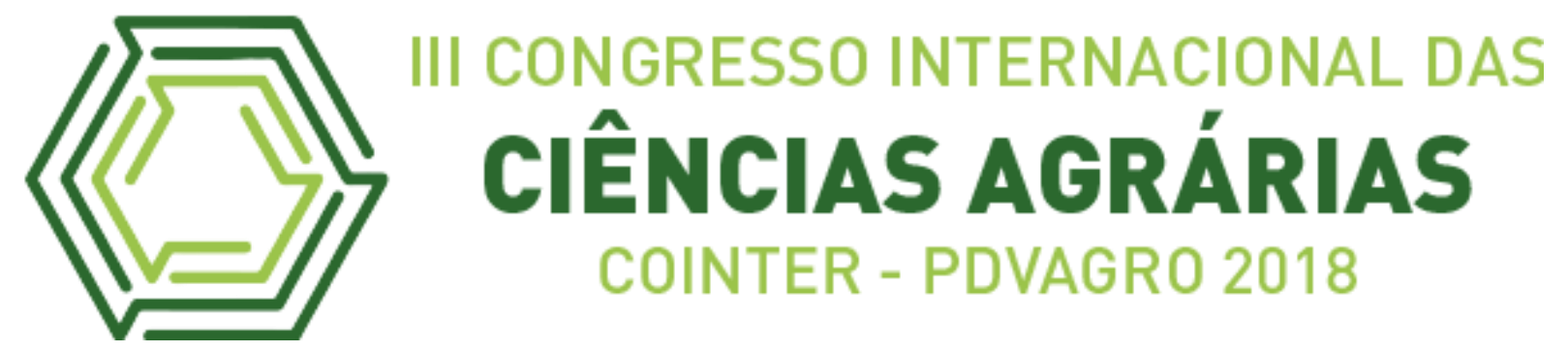

\title{
TIPO DE ESTACA E ESPAÇAMENTO DE GLIRICÍDIA (GLIRICIDIA SEPIUM (JACQ.) WALP.) NA PRODUÇÃO DE JARDIM CLONAL PARA TUTOR VIVO NO CULTIVO DA PIMENTEIRA-DO-REINO (PIPER NIGRUM L.)
}

Apresentação: Pôster

Fernanda Beatriz Bernaldo da Silva ${ }^{1}$, Danielle Pereira Mendonça ${ }^{2}$, Marcília Gabriella

Tavares Monteiro ${ }^{3}$, Ana Carolina Melo Ribeiro ${ }^{4,}$ Oriel Filgueira de Lemos ${ }^{5}$

DOI: https://doi.org/10.31692/2526-7701.IIICOINTERPDVAGRO.2018.00677

\section{Introdução}

A espécie gliricídia (Gliricidia sepium (Jacq.) Walp.) é uma planta nativa da América do Sul e Central, uma leguminosa arbórea de uso múltiplo mais cultivada nas regiões tropicais. (Simons \& Stewart, 1994). Esta espécie é usada para sombreamento de cacaueiros, como cerca viva, como madeira ou lenha e na produção de forragem para alimentação animal (Baggio, 1984). No cultivo da pimenteira do reino (Piper nigrum L.) que precisa de suporte para crescer, a gliricídia (Gliricidia sepium (Jacq.) Walp.) é utilizada como tutor vivo, uma alternativa ao uso do tutor morto (estacão de madeira) que apresenta grandes dificuldades para aquisição e elevados preços, com vantagens de redução dos custos de implantação, impactos ambientais e aumento da longevidade dos pimentais que podem ser facilmente adotados por agricultores familiares. O experimento foi desenvolvido no campo experimental da Embrapa Amazônia Oriental. Foram testados três espaçamentos. $(1 \times 0.5,1 \times 1,1 \times 1.5 \mathrm{~m})$ e dois tipos de estacas (Apical e Basal). Observou-se que o espaçamento para a formação do jardim clonal de 1,0x1,0m proporcionou maior diâmetro das estacas para a disponibilização de estacas como tutor vivo para o plantio de pimenteira-do-reino. Quanto à origem das estacas, aquelas da parte basal mostraram um maior desempenho a partir das médias obtidas no experimento. Portanto, para a formação do jardim clonal para geração de estacas de gliricídias para o plantio de pimenteira-do-reino sugere-se espaçamento de $1,0 \mathrm{X} 1,0 \mathrm{~m}$ e estacas basais que proporcionam boa brotações e diâmetro dos brotos. Portanto, o objetivo desse trabalho foi avaliar qual o espaçamento e tipo de estaca mais apropriados para a formação de jardim da

\footnotetext{
${ }^{1}$ Graduanda em agronomia, Universidade Federal Rural da Amazônia-UFRA, Fernanda_bernaldo@hotmail.com

${ }^{2}$ Graduanda em agronomia, Universidade Federal Rural da Amazônia-UFRA, Daniellepereir@gmail.com

${ }^{3}$ Doutoranda em agronomia, Universidade Federal Rural da Amazônia-UFRA, Gabytavares15@hotmail.com

${ }^{4}$ Graduanda em agronomia, Universidade Federal Rural da Amazônia-UFRA, Carolm.ribeiro95@gmail.com

${ }^{5}$ Doutor, Escola Superior de Agricultura Luiz de Queiroz-Esalque,Oriel.lemos@embrapa.br
} 
gliricídia para produção de estacas como tutor da pimenteira-do-reino.

\section{Fundamentação Teórica}

A espécie gliricídia (Gliricidia sepium (Jacq.) Walp.) é usada para sombreamento no cultivo da pimenteira-do-reino (Piper nigrum L.) sendo então um tutor vivo como alternativa na substituição do tutor morto (madeira), pelas dificuldades na obtenção de estacões e também, pelo altos preços. Enquanto as estacas de gliricídia, como tutor vivo, apresentam vantagens de redução dos impactos ambientais e aumento da longevidade dos pimentais. $\mathrm{O}$ uso da gliricídia como tutor vivo para cultivo da pimenteira-do-reino é uma tecnologia menos onerosa que pode ser facilmente desenvolvida por agricultores familiares. (MENEZES et al., 2003). Por ser leguminosa, a gliricídia tem demonstrado grande potencial como fornecedora de nitrogênio ao solo, podendo substituir total ou parcialmente o uso de fertilizantes nitrogenados, aumento o teor de matéria orgânica no solo, a diversidade biológica além de proporcionar conforto ambiental aos trabalhadores rurais.

\section{Metodologia}

O experimento foi desenvolvido no campo experimental da Embrapa Amazônia Oriental. Os tratamentos testados foram a combinação de três espaçamentos. $(1 \times 0.5,1 \times 1$, $1 \mathrm{x} 1.5 \mathrm{~m}$ ) e dois tipos de estacas (Apical e Basal). Foram utilizadas estacas com tamanhos padrões de 1,20m que foram plantadas à profundidade de $50 \mathrm{~cm}$ abaixo do solo, com diâmetro de $5 \mathrm{~cm}$. Após 6 meses do plantio foram realizadas as avaliações quanto ao diâmetro das estacas. Para a mensuração do diâmetro da estaca foi utilizado um paquímetro digital (KINGTOOLS, precisão de 0,01 mm). O delineamento foi inteiramente casualizado em fatorial $3 \times 2$ com 25 repetições e a variável avaliada foi o diâmetro da estaca. Os dados foram submetidos à análise estatística de variância e teste de comparação de média de tukey a 5\% de probabilidade.

\section{Resultados e Discussões}

Houve diferença significativa entre os tratamentos, nos quais foi observado que o espaçamento entre estacas de 1x1.0m mostrou aumento de diâmetro das estacas de gliricídia. De acordo MENEZES et al., (2003), as estacas de gliricídia para cultivo da pimenteira-doreino são plantadas no espaçamento de $2,25 \mathrm{~m}$ x $2,25 \mathrm{~m}$ X 4,0m, das quais podem ser obtidas estacas para novos plantios. No entanto, no trabalho verificou-se que a medida que se 
aumenta o espaçamento há um decréscimo no desenvolvimento do diâmetro (Tabela 1). Desta forma, os resultados mostraram que é possível a otimização da área para produção de novas estacas de gliricídia para o plantio da pimenteira-do-reino com redução de espaçamento. Quanto a procedência das estacas, as de origem basal mostraram um melhor desempenho (Tabela 2). Com relação à densidade de matéria seca das brotações, as estacas basais e medianas-basais foram superiores às mediana apicais e apicais, o que levou a conclusão de que quanto mais próximo da base do ramo, maiores são as condições que elas têm para a formação da muda (CHAVES, et al 2016). A média para o número de brotos para os dois tipos de estacas utilizados não diferem estatisticamente entre si. Esse resultado se difere do que foi apresentador por CHAVES et al, 2016 que afirma que as estacas obtidas a partir da base dos ramos apresentaram maiores taxas de brotação quando comparadas às estacas obtidas do ápice dos ramos da planta matriz.

Tabela 1. Diâmetro das estacas de gliricídia após 6 meses do plantio em três espaçamento.

\begin{tabular}{cccc} 
& \multicolumn{3}{c}{ Espaçamentos das estacas } \\
\cline { 2 - 4 } & $1 \times 0.5$ & $1 \times 1.0$ & $1 \times 1.5$ \\
\hline Média & $57,87 \mathrm{~B}$ & $61.74 \mathrm{~A}$ & $54.05 \mathrm{C}$
\end{tabular}

Médias seguidas da mesma letra não são significativas entre si, pelo teste de Tukey a $5 \%$ de probabilidade.

Tabela 2. Média para os dois tipos de estacas utilizadas.

\begin{tabular}{ccc}
\hline & \multicolumn{2}{c}{ Tipos de estacas } \\
\cline { 2 - 3 } & Apical & Basal \\
\hline Média & $56,26 \mathrm{~B}$ & $59.71 \mathrm{~B}$ \\
\hline
\end{tabular}

Médias seguidas da mesma letra não são significativas entre si, pelo teste de Tukey a 5\% de probabilidade.

Tabela 3. Média do número de brotos para os dois tipos de estacas.

\begin{tabular}{ccc}
\hline & \multicolumn{2}{c}{ Número de Brotos } \\
\cline { 2 - 3 } & Apical & Basal \\
\hline Média & 10,58 & 10,58
\end{tabular}

Não diferem estatisticamente entre si.

\section{Conclusões}

Para formação de jardim clonal de gliricídia visando à formação de estacas como tutor vivo para o cultivo da pimenteira-do-reino o espaçamento de $1 \times 1.0 \mathrm{~m}$ e o uso de estacas do 
tipo basal são mais adequados considerando.

\section{Referências}

BAGGIO, A.J. Possibilidades de Gliricidia sepium para uso em sistemas agroflorestais no Brasil. Pesquisa Agropecuária Brasileira. v.19, sn, p.24-243, 1984

CHAVES, Propagação vegetativa de espécies florestais com potencial para uso como cerca viva. dissertação mestrado 07p. Universidade Federal Rural Do Rio De Janeiro. Instituto De Agronomia. 2017

Antônio José Elias Amorim de Menezes. Gliricídia como tutor vivo para pimenteira-do-reino - Belém, PA. Documentos Embrapa Amazônia Oriental, 2013. 31p. ISSN 1983-0513; 393.

IMONS, A.J.; STEWART, J.L. Gliricidia sepium, a multipurpose forage tree legume. In: GUTTERIDGE, R.C.; SHELTON, H.M. (Eds.) Forage tree legumes in tropical agriculture. Wallinford: CAB International, 1994. p.30-48. 